\title{
RÉGIMEN LEGISLATIVO Y DE PROPIEDAD DURANTE LA Revolución MeXicana: Los Casos de laS haCiendas PETROLERAS de Chapopote y El Álamo, EN EL NORTE VERACRUZANO (1925-1937)
}

\author{
Legislative regime and property during the Mexican Revolution: \\ The cases of the petroleum farms of Chapopote and El Álamo \\ in the north of Veracruz (1925-1937)
}

\section{CÁndido Eugenio Aguilar AguilaR*}

\section{RESUMEN}

Este artículo tiene como principal objetivo mostrar el proceso de regulación legislativa y jurídica de la industria petrolera en México durante el periodo revolucionario. La metodología seguida consistió, en primer lugar, en analizar la construcción del Estado revolucionario a partir del control y administración del recurso petrolero con base en la aplicación del artículo 27 constitucional y, en segundo lugar, en estudiar la influencia de las leyes porfiristas en el régimen de propiedad que se mantuvo en las haciendas petroleras mexicanas, las cuales estuvieron estrechamente ligadas tanto al arrendamiento como a la inversión extranjera.

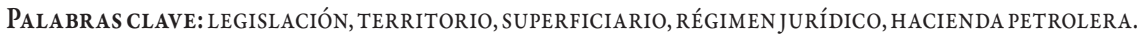

\section{Abstract}

This article has as main objective to show the process of legislative and legal regulation of the oil industry in Mexico during the revolutionary period. The methodology followed was first to examine the construction of the revolutionary state from the control and management of the oil resource based on the application of article 27 of the Constitution and, secondly, the influence of the porfiristas laws on the property regime remained in Mexican oil estates, which were closely linked to the lease as to foreign investment.

KEYWORDS: LEGISLATION, TERRITORY, SUPERFICIARY, LEGAL REGIME, OIL LAND.

Recepción: 3 de febrero de 2016.

Dictamen 1: 4 de abril de 2016.

Dictamen 2: 16 de mayo de 2016.

Dictamen 3: 27 de mayo de 2016.

* ElColegio deSan Luis, Doctorado en Ciencias Sociales.Correo electrónico: caeg.boreal.81@gmail.com. 


\section{INTRODUCCIÓN}

El presente artículo pone en el centro del análisis las dificultades por las que atravesó el proceso legislativo revolucionario con respecto de la industria petrolera en México. En primer lugar, se muestra la complicada labor del Estado revolucionario por ejercer la Constitución de 1917; por otro lado, se expone de manera especial el caso de los propietarios particulares como mediadores de la riqueza petrolera. En ese sentido, se propone una revisión documental y bibliográfica que permita distinguir el tipo de régimen de propiedad y jurídico petrolero que imperó durante el periodo revolucionario, así como destacar la importancia de las leyes porfiristas como referente legislativo.

Nuestro análisis aborda la disputa por el control y administración del recurso petrolero en el norte del estado de Veracruz entre 1925 y 1937, que implicó una lucha por la posesión y usufructo de la tierra. Este fenómeno será ejemplificado mediante los recursos jurídicos utilizados por la familia Núñez en contra de la compañía petrolera Penn Mex Fuel Company y del gobierno mexicano en defensa de las haciendas petroleras de Chapopote y El Álamo, cuyos escenarios nos muestran perfectamente el tipo de régimen legislativo y de propiedad prevaleciente durante el periodo revolucionario, así como su relación con el transitorio Estado mexicano.

Esta mirada histórica nos permitirá una mejor comprensión del proceso jurídico de la industria privada del petróleo en México durante la Revolución, sobre todo si tomamos en cuenta que desde la primera década del siglo XX las compañías petroleras extranjeras fueron beneficiadas gracias a las concesiones porfiristas, las cuales, a su vez, ofrecieron ventajas sobre el derecho de propiedad y el subsuelo. Sin embargo, las posteriores reformas y decretos que los sucesores de Porfirio Díaz intentaron aplicar en materia de extracción y explotación petrolera propiciaron un conflicto entre el gobierno mexicano y las compañías que, al menos hasta la década de 1920, resultó favorable para estas últimas.

Como resultado de la inestabilidad política y económica que causó la Revolución, se entramó una serie de acontecimientos nacionales e internacionales que incidieron, entre otras cosas, en las actividades sociales y económicas del estado de Veracruz que giraban en torno al petróleo. En esta entidad, las compañías petroleras ya habían iniciado trabajos de exploración en el norte de su jurisdicción. La mayoría de los iniciales contratos de arrendamiento de tierras y las concesiones de explotación acordados por las compañías con el gobierno mexicano y superficiarios tenían como principal respaldo las leyes porfiristas que autorizaban la extracción 
del combustible que se hallaba en propiedades de los concesionarios facultados por el titular del Ejecutivo.

Las ventajas que desde entonces tuvieron las compañías fueron notables frente a un gobierno mexicano que enfocó su atención en resolver la situación política y económica interna. En este derrotero coincidieron muchos factores políticos, económicos y legislativos que impidieron que la Constitución de 1917 se ejerciera a plenitud frente al poderío territorial y económico de las compañías petroleras y a la legislación porfirista que facilitó la privatización de la tierra por parte de las familias de poder, comúnmente llamadas terratenientes y jurídicamente mencionadas bajo el nombre de superficiarios.

\section{LEGISLACIÓN Y TERRITORIO NACIONAL:}

\section{LA ENCRUCIJADA REVOLUCIONARIA}

La modernización de México durante el gobierno de Porfirio Díaz requirió de su inclusión al sistema económico mundial entre finales del siglo XIX y principios del XX. El grupo de científicos que promovió esta política económica estaba convencido de que México debía ser impulsado a través de una ideología de orden y progreso, cuyo estado evolucionista había cumplido su etapa álgida tras el triunfo de liberalismo mexicano (Zea, 1968, pp. 233-285).

Este liberalismo desarrollista propugnó el establecimiento y defensa de la propiedad privada y el libre flujo de mercancías, así como la fragmentación de la propiedad comunal y la centralización administrativa de la riqueza nacional. En este proceso fue necesaria la aplicación de un conocimiento territorial que permitió dimensionar las riquezas naturales que pudieran ser extraídas, entre las cuales se encontraba el petróleo (García, 2009, p. 88).

El proyecto de modernización nacional logró vincular económicamente los centros de producción con los lugares de consumo a través de vías de comunicación. Esta vinculación permitió consolidar el dominio de la clase porfirista con respecto de los poderes locales, así como diseñar nuevos alcances territoriales una vez que se canalizó la producción nacional hacia el exterior (García, 2009, p. 88).

$\mathrm{Al}$ amparo de este proyecto modernista, se formularon leyes que protegieron la inversión extranjera y la propiedad privada, que influyeron en la definición de nuevas delimitaciones territoriales, como fue el caso de la industria petrolera. En primer orden, fueron decretadas las leyes del Código Minero de 1884 y 1892, las cuales 
otorgaron derechos de explotación de recursos naturales del subsuelo a inversionistas extranjeros y a los dueños de tierras, así como concesiones y derechos de expropiación en caso de haber terrenos baldíos. Mientras que en el aspecto fiscal, se les eximía de pagos de impuestos de importación por la introducción de equipo, sin importar cualquier contribución de exportación de productos (Pemex, 1988, pp. 57-58).

Nueve años después se decretó la Ley del 26 de diciembre de 1901, la cual autorizaba concesiones a compañías petroleras permitiéndoles, entre otras cosas, "exportar libre de impuestos toda la producción, así como importar maquinaria para transportar y refinar el petróleo”. Asimismo, concedía al superficiario el petróleo y demás sustancias que se encontraran en su propiedad, "sin necesidad de que fueran denunciadas y sin que fuera necesario obtener una adjudicación espacial para su explotación" (Bassols, 2006, pp. 9-14).

Con la autorización de la ley de 1901, el gobierno del estado de Veracruz llevó a cabo contratos durante los primeros años del siglo XX a través de los cuales se cedían a las compañías petroleras los derechos de exploración y explotación del subsuelo de los terrenos vacantes adquiridos por sentencia ejecutoria. Para que las compañías petroleras gozaran de dichos derechos y franquicias, debían manifestar al gobierno cuáles eran las negociaciones, terrenos, pozos de petróleo, instalaciones y fábricas que tenían en arrendamiento. Las compañías podían ocupar los terrenos pertenecientes al estado siempre y cuando no estuvieran destinados al uso público. En caso de que las propiedades fuesen de los ayuntamientos, la gestión tenía que hacerse ante las corporaciones municipales respectivas para resolver el caso con aprobación del Ejecutivo. La duración de este contrato tenía validez por cincuenta años, que contaba a partir de la fecha de su promulgación como decreto aprobatorio en el Periódico Oficial (AGEV, fondo Fomento, caja 173, exp. 24).

Posteriormente, en La ley de 1909 se estableció la "propiedad exclusiva del dueño del suelo todas las formas minerales combustibles, así como la facultad de explorar y explotar libremente el petróleo, sin necesidad de permiso de autoridad alguna" (Bassols, 2006, pp. 16-17). Esta ley en particular benefició a dos grupos principalmente: 1) los superficiarios o dueños de la superficie, los cuales llevaron a cabo contratos de compraventa o arrendamiento con las compañías petroleras para la exploración y explotación; 2) las compañías petroleras, que eran las principales beneficiadas económicamente de la explotación.

La apertura a la inversión extranjera y a la explotación privada de los recursos naturales formaron parte de un marco legislativo que rompió históricamente con las leyes hispanoamericanas, para fijar su atención en la legislación anglofrancesa, 
la cual atribuía "la propiedad del fluido al dueño de la tierra". Esta modificación postuló la idea de que la nación era dueña del petróleo, por lo cual tocaba turno a los nacionales de dirigir los destinos administrativos de su explotación. Ser dueño no significaba ser el poseedor absoluto de la riqueza y del control económico, sino más bien el regulador de las actividades petroleras que establecían las leyes, las cuales dependían de las decisiones del Estado mexicano (Bassols, 2006, pp. 9-10). De esta manera, las leyes porfiristas influyeron en la expansión territorial de las compañías petroleras durante los procesos de unificación industrial, no obstante los cambios políticos ocurridos con motivo de la Revolución mexicana.

A pesar de que el gobierno porfirista había llegado a su fin, entre 1911 y 1918 la industria petrolera no solo se mantuvo, sino que logró extenderse a lo largo de las zonas potenciales petrolíferas. Un primer factor que facilitó la prolongación de la actividad privada petrolera fue la inestabilidad política que perduró durante la Revolución, y un segundo factor fue el estallido de la Primera Guerra Mundial (1914-1918).

La inestabilidad política ayudó a que los vínculos económicos entre la clase terrateniente y las compañías petroleras se fortalecieran. El frágil y efímero régimen revolucionario fue incapaz de controlar administrativamente la explotación petrolera, mucho menos de regular el mercado de tierras. Este vacío de poder permitió a la clase terrateniente de la Huasteca veracruzana tener un mayor dominio político y económico sobre su espacio de influencia. La clase terrateniente estaba compuesta en su mayoría por familias que habían afincado su poder desde la segunda mitad del siglo XIX a través de la explotación de recursos naturales, como fue el caso de los Núñez, Gorrochotegui, Peláez, Basáñez y Chao. Los vínculos directos generados con las compañías los condicionó como los verdaderos intermediarios de la riqueza, mientras que las compañías lograron explotar con mayor libertad la región petrolera. Los vínculos contribuyeron a dos cosas: 1) formar un grupo de Guardias Blancas a iniciativa de los líderes de familias terratenientes como Manuel Peláez, ${ }^{1}$ con el fin de defender los intereses petroleros, y 2) lograr la mayor posesión de tierras por parte de las compañías.

\footnotetext{
1 Manuel Peláez provenía de una familia de españoles que, gracias a las actividades comerciales desarrolladas desde el siglo XIX, logró consolidarse dentro del grupo de poder de Tuxpan, como también lo hizo la familia Núñez. Entre sus integrantes figuraron Gabriel y Manuel Gorrochotegui (tío y abuelo de Manuel Peláez, respectivamente), quienes fueron jefes políticos de Tuxpan en el periodo porfirista, y en el caso de Manuel, cacique de Tantoyuca. La familia contaba con un clientelismo político proveniente del pueblo de Temapache, debido a que los Gorrochotegui apoyaron en varias ocasiones a los indígenas en asuntos de tierras. La familia Peláez y Gorrochotegui era dueña de los terrenos de Tierra Amarilla, Palma Real, Llano Grande y Cuchilla del Pulque. Las tierras estaban ubicadas en el municipio de Temapache y colindaban con los predios de Tepetzintla, Potrero del Llano y Cerro Azul, los cuales estaban también en actividad petrolera. Estas tierras se hallaban al norte de las
} 
Los sucesos nacionales e internacionales provocaron serios cambios territoriales y sociales en las zonas petrolíferas de México, como fue el caso de la Faja de Oro, ${ }^{2}$ considerada hasta la década de 1920 como una de las regiones más productivas del mundo gracias a su desarrollo industrial. Un ejemplo de ello fue la facilidad con que la industria petrolera se extendió entre las jurisdicciones municipales de Tuxpan y Temapache para dar salida comercial al petróleo con destino a Europa y Estados Unidos. Uno de los principales motivos que dio cabida al acelerado proceso de industrialización de la zona rural fue la capacidad negociadora que tuvieron familias terratenientes como los Núñez para permitir la apertura de espacios petroleros en Temapache, municipio que estaba regido por un régimen de propiedad particular.

El acaparamiento de tierras petrolíferas del estado de Veracruz, junto con las condiciones geográficas del mismo estado, crearon las circunstancias apropiadas para la extensión de la industria petrolera. Por un lado, la constancia de la aplicación de las leyes porfiristas promovió un mercado de tierras (compra, renta y despojo), y por otro, las regiones petroleras tenían una relativa cercanía con el Golfo de México, situación que propició un mayor alcance de la industria, entendida esta como la unificación de un conjunto de procesos involucrados en la exploración, explotación y refinación, caracterizados por un origen, migración, acumulación, detección, extracción y transporte del petróleo (García, 1989, pp. 19-22).

Las compañías lograron un control sobre el derecho del subsuelo en la medida de la capacidad de la posesión de la tierra. Basta decir que, hacia 1906, la compañía El Águila, propiedad de Weetman Pearson, logró hacerse de 243000 hectáreas de tierra en regiones petrolíferas de Tabasco, Campeche y Veracruz, mientras que para 1911 el número de hectáreas aumentó a 679069 (Garner, 2007, pp. 226-227). Esto no significa que en la mayoría de los casos las compañías hayan recurrido al despojo de tierras comunales, o bien a la compra directa, como ocurrió en un principio. Un tercer recurso fue el arrendamiento de tierras, pues los alcances de los contratos entre terratenientes y compañías también posibilitaron procesos de exploración, explotación y refinación. Lo importante era obtener tierras por cualquier vía. El empresario Weetman Pearson lo tradujo de la siguiente manera:

\footnotetext{
haciendas de la familia Núñez, las más extensas del municipio de Temapache (AHP, Fondo Expropiación, caja 874, exp. 22758).

2 La Faja de Oro es un término geológico que definía un área específica de 300 kilómetros de largo y 75 kilómetros de ancho, conocida como Línea de Ham o Golden Lane, cuya estructura petrolífera se extendía sobre los puntos de San Diego de la Mar, Tepetate, Juan Casiano, Naranjos, Chinampa, Amatlán, Cerro Azul,Zacamixtle, Toteco, San Jerónimo Tierra Amarilla, Potrero del Llano, Molino, Álamo, hasta llegar a San Isidro, al sur del río Tamesí; es decir, abarcaba los municipios de Chinampa, Tantoco, Amatlán, Tepetzintla, Naranjos, Temapachey Castillo de Teayo, en el norte del estado de Veracruz (López, 1975).
} 
[...] los yacimientos de petróleo se extienden frecuentemente en zonas muy grandes, por lo que los derechos sobre el petróleo deben abarcar una superficie muy vasta para que sea realmente valiosa. Cuatro mil, ocho mil o dieciséis mil hectáreas parecen ser una extensión no poco común; por lo que, al obtener una opción, obténgala sobre un territorio tan grande como sea posible (Garner, 2007, pp. 149-150).

En los contratos de arrendamiento, las familias terratenientes acordaron ceder a las compañías el derecho de hacer "uso gratuitamente de la superficie de terreno necesaria para las instalaciones de maquinarias, tanques de depósito, presas, estaciones para bombas y otras mejoras necesarias en las operaciones del concesionario", como era el hecho de construir líneas de tubería a lo largo del terreno, edificios para oficinas, almacenes y habitaciones para los trabajadores, así como abrir y construir toda clase de vías de comunicación con sus respectivos usos y derechos. ${ }^{3} \mathrm{Al}$ no estar sujeto el establecimiento de la infraestructura petrolera a patrones preconcebidos de diseño o dimensión de la región petrolífera, la tarea de uniformar el proceso industrial terminó por acaparar un mayor porcentaje de tierras.

Las compañías petroleras extranjeras lograron ampliar su espacio de influencia bajo el ejercicio de las leyes porfiristas y los contratos de arrendamiento. Adaptaron también el proceso industrial a las características geográficas del estado de Veracruz, al grado de delimitar un territorio que rebasaba las fronteras estatales. La delimitación territorial comprendió casi todo el norte del estado de Veracruz, desarrollada en función de una infraestructura de transporte y refinación que obligaba a los espacios extractivos a mantener una especie de contacto industrial, laboral y entre poblaciones.

Si bien es cierto que el porfiriato no representó la etapa cúspide de la producción petrolera en México, también es verdad que, en el marco legislativo, las compañías petroleras siguieron operando bajo los acuerdos de las leyes porfiristas, a pesar de que en 1917 ya se había decretado una Constitución nacional. ${ }^{4}$

La Constitución de 1917 fue producto de una necesidad del momento revolucionario, que intentó pacificar a la nación y reestructurar el territorio en términos

\footnotetext{
3 El terreno para oficinas y habitaciones mencionado no excedería en cada pozo la extensión de seis hectáreas (AHP, Fondo: Expropiación, caja 1321, exp. 36359, ff. 10-11).

${ }^{4}$ Lorenzo Meyer propone un división cronológica de cuatro etapas para la industria petrolera: la primera se refiere alas postrimerías del porfiriato, cuya etapa de producción fue hasta cierto punto baja y de lento crecimiento; la segunda y más importante, considerada como la "etapa dorada”, se caracterizó por una asombrosa producción entre 1911 y 1921, cuando solo Estados Unidos pudo superar a México en dicho rubro; la tercera, de 1922 a 1932, refleja una considerable caída en la producción, y la cuarta comenzó desde 1933 y terminó hasta 1938, justo cuando la industria petrolera se nacionalizó y en la que se observa una ligera recuperación en el nivel productivo (Meyer, 1972, p. 23).
} 
petroleros, pero la premura y la división política en el interior de las facciones dificultó el proceso, como el hecho de desvanecerse el posible ejercicio constitucional del concepto de "tierras nacionales" en términos de exploración y explotación petrolera. Por el contrario, la legislación porfirista que incentivó el régimen de propiedad privada y el mercado de tierras (compra, despojo y arrendamiento) con fines petroleros fue tan real que las firmas Pearson, Doheny y Transcontinental "no sólo siguieron ocupando sus propiedades petroleras y aprovechando sus contratos, sino que se lanzaron a una ilimitada explotación de los yacimientos, en una época en que ya era evidente la conveniencia de extraer petróleo en forma unificada" (Bassols, 2006, p. 29).

Mientras que el gobierno porfirista se caracterizó por ser receptor de la inversión extranjera y regulador legislativo de las actividades económicas petroleras, el gobierno revolucionario construyó su imagen con base en intentos forzados por controlar administrativamente el territorio mediante un marco legislativo creado en su propio seno. Esto se debió al extremo logro de la inversión extranjera que condicionó el territorio a voluntad del uso y explotación de los recursos naturales. La visión territorial porfirista de unión nacional también desarrolló a tal grado una unificación de los procesos de exploración, explotación y refinación petrolera que desmantelar el proyecto de modernización y colonización extranjera fue una tarea monumental para el emergente Estado revolucionario. A marchas forzadas, el Ejecutivo revolucionario finalmente logró fortalecer su condición como representante del pueblo con la ayuda de la Constitución de 1917. En adelante, se nacionalizó el territorio con el apoyo de un "discurso escrito y gráfico políticocultural, de carácter constitucional, que desplegó una visión territorial con un fuerte acento mítico, de alta densidad simbólica” (García, 2009, p. 187). El discurso del uso del territorio en beneficio de la nación quedó expresado en el artículo 27 de la Constitución de 1917, la cual fue diseñada y promovida por el gobierno de Venustiano Carranza:

Corresponde a la Nación el dominio de todos los minerales o substancias que en vetas, mantos, masas y yacimientos, constituyan depósitos cuya naturaleza sea distinta de los componentes de los terrenos, tales como los minerales de los que extraigan metales y metaloides utilizados en la industria; los yacimientos de piedras preciosas, de sal de gema y salinas formadas directamente por las aguas marinas, los productos derivados de la descomposición de las rocas, cuando su explotación necesite trabajos subterráneos; los fosfatos susceptibles de ser utilizados como fertilizantes, los combustibles minerales sólidos; el petróleo y todos los 
carburos de hidrógeno sólidos, líquidos o gaseosos (Constitución Política de los Estados Unidos Mexicanos, 1934, p. 4).

La homogeneidad de la legislación porfirista permitió un margen mayor del uso de la llamada sustancia bituminosa o petróleo, pues se consideraba, al igual que los recursos minerales, un producto de las tierras nacionales, en donde la inversión extranjera tenía prioridad. El proceso de unificación industrial fue facilitado gracias a un previo consumo del conocimiento tecnológico de las nuevas formas de aprovechar el territorio.

El consumo del conocimiento tecnológico y el ejercicio de las leyes porfiristas durante la Revolución beneficiaron la extensión industrial de las compañías petroleras en el territorio mexicano. Jonathan Brown puntualiza que en este proceso influyó la situación interna de México, el mercado internacional y la postura política de los gobiernos revolucionarios. La influencia de estos factores fue vital en la actividad petrolera y en la relación entre las compañías y el Estado mexicano, sobre todo porque se trata de un periodo en el que el desarrollo capitalista y la regulación de la industria petrolera se sujetaron a los intereses de las facciones políticas mexicanas (Brown, 1998).

Por su parte, Narciso Bassols afirma que el Ejecutivo fue ineficiente política y administrativamente al momento de distribuir la riqueza petrolera con atención social. Esta visión estuvo vinculada a una cultura legislativa emergente y apresurada, que se exteriorizó con el gobierno porfirista al aislar a la sociedad mexicana de los beneficios de la explotación petrolera y sustituir el poder central de la vieja monarquía por uno patriarcal. El Antiguo Régimen se olvidó de incentivar la inversión mexicana en asuntos petroleros, lo que desembocó en un control territorial y social exento del derecho común e indefenso ante la postura avasalladora de las compañías petroleras. El espíritu de las leyes mexicanas fue excluyente, elitista, monárquico y poco distributivo. Si bien el Estado revolucionario creó un discurso nacionalista que contrastó con la privatización extranjera, también es cierto que al final solo fortaleció las funciones del Ejecutivo (Bassols, 2006).

La introducción del conocimiento técnico del petróleo repercutió con gran fuerza, al grado de generar entre la opinión pública altisonantes discursos de prosperidad, otrora mesuradas menciones de una industria en apariencia prometedora. La siguiente cita del periódico Excélsior del año de 1922 dice mucho con respecto del incentivo de la inversión extranjera y la explotación petrolera en México: 
Cada vez se evidencia más el dolo de las versiones propaladas tanto en este país como en el extranjero acerca del agotamiento de nuestro petróleo que es por hoy la riqueza nacional más fabulosa.

Muy lejos están de extinguirse nuestras zonas productoras de aceite mineral, como lo demuestran las notas estadísticas que insertamos a continuación, y por consiguiente garantizada está también esa riqueza nacional que margen ha dado y grande a los financieros de aquende y allende el Bravo para realizar el amparo de falsar versiones magnas operaciones.

En este contexto, el artículo 27 de la Constitución de 1917 proponía una nueva forma de concebir lo que jurisdiccionalmente le pertenecía a la nación para explotar sus recursos naturales, pero el contexto político y económico sobre el que se pretendía legislar era desfavorable: no había un soporte nacional de infraestructura petrolera y el Ejecutivo aplicaba la ley pensando en la recaudación fiscal a partir del concepto de propiedad de la nación, cuando la riqueza del subsuelo era todavía disputable en tierra y jurisdicción de superficiarios.

Para Lorenzo Meyer, en este periodo, el juego expansionista de la industria petrolera tuvo gran repercusión permitiendo a Estados Unidos reducir la capacidad negociadora de México de la explotación de los hidrocarburos, mientras que este último país se vio en la necesidad de ceder derechos a los estadounidenses para que explotaran recursos naturales y de esta manera solventar parte de la crisis económica que se desató con el caos revolucionario (Meyer, 1972).

A pesar de la complicada situación económica imperante en México, de la crisis social que se desató y de los ingresos económicos que las compañías dejaron al gobierno obregonista (1920-1924) — causa principal de las holgadas operaciones de explotación petrolera en el país-, las leyes petrolíferas se volvieron a tomar durante el gobierno de Plutarco Elías Calles (1925 y 1926), quien dos años después apoyaría el Reglamento de Trabajos Petroleros, el cual establecía medidas en beneficio de la nación, tales como la prevención de accidentes, el comercio y distribución de productos. En la Ley y Reglamento sobre petróleo de 1925, por ejemplo, en su artículo $1^{\circ}$ se lee: "Corresponde a la Nación el dominio directo de toda mezcla de carburos de hidrógeno que se encuentren en su yacimiento, cualquiera que sea su estado físico. En esta ley se comprende la palabra 'Petróleo', a todas las mezclas naturales de hidrocarburos que lo componen, lo acompañan o se derivan de él” (Ley y Reglamento sobre Petróleo, Diario Oficial, 31 de diciembre de 1925, pp. 295-296).

El artículo $4^{\circ}$ de la misma ley de 1925 establecía que las sociedades civiles y comerciales y los mexicanos podían obtener concesiones petroleras, siempre y cuando 
estuvieran constituidas con base en las leyes mexicanas, mientras que los extranjeros tendrían que cumplir con lo prescrito en el artículo 27 de la Constitución. Asimismo, el artículo $7^{\circ}$ instituía que si había oposición del superficiario, la Secretaría de Industria, Comercio y Trabajo podría fungir como árbitro, si en todo caso convenían el explorador y el superficiario; de lo contrario, el Ejecutivo Federal se daría a la tarea de ocupar y expropiar los terrenos, de acuerdo con las necesidades de la industria petrolera, garantizando la indemnización del superficiario por daños y perjuicios. ${ }^{5}$

La ley orgánica propuesta por el gobierno de Calles en 1925 tenía por objeto reducir la capacidad de dependencia, no solo con respecto de las compañías, sino también del gobierno norteamericano, acción que fue calificada como anticapitalista. A pesar de que en un principio la labor del gobierno callista por escindir los consorcios petroleros parecía lograr el objetivo, la posición del petrolero Doheny de no cumplir con las modificaciones legislativas abatió el proyecto revolucionario que tenía por objeto hacer que las compañías cumplieran las nuevas disposiciones propuestas en la ley de 1925. Al inicio, las compañías Royal Dutch y Transcontinental estuvieron dispuestas a aceptar las disposiciones; sin embargo, las conferencias entre petroleros celebradas desde 1926, así como el seguimiento de compañías como El Águila a la posición de Doheny, encaminaron la ley petrolera mexicana a una controversia (Meyer, 1972, pp. 233-241).

Fue justamente a partir de la ley expropiatoria del 18 de marzo de 1938, decretada durante el gobierno de Lázaro Cárdenas, ${ }^{6}$ cuando el Estado mexicano

\footnotetext{
5 Elartículo $8^{\circ}$ del Reglamento de la Ley del Petróleo de 1926 especificaba que en toda solicitud de concesión petrolera el interesado debía expresar - además del nombre, la nacionalidad, la edad y el domicilio-la naturaleza de la concesióny los fundamentos para obtenerla, el nombre del lote o los lotes que soliciten en concesión, ubicación y linderos del lote o lotes, superficie de cada uno y la especificación de sise trata de propiedad particular o jurisdicción federal. Para tener un mayor control de las actividades industriales del petróleo, el artículo $2^{\circ}$ señalaba que las agencias de petróleo "dependerán directamente del Departamento del Ramo, de la Secretaría de Industria, Comercioy Trabajo y las ya establecidas". Entre estas se encontraba la Agencia en Tampico que operaba en la Huasteca veracruzana, en los excantones de Ozuluama, Tantoyuca, Tuxpan, Chicontepecy Papantla (Ley y Reglamento sobre Petróleo, 1925, p. 297; Reglamento de la Ley del Petróleo, Diario Oficial, 8 de abril de 1926, pp. 306-308).

6 El decreto establecía: "Se declaran expropiados por causa de utilidad pública y a favor de la Nación, la maquinaria, instalaciones, edificios, oleoductos, refinerías, tanques de almacenamiento, vías de comunicación, carrostanque, estaciones de distribución, embarcaciones y todos los demás bienes muebles e inmuebles de la propiedad de: la Compañía Mexicana de Petróleo El Águila, S. A., Compañía Naviera de San Cristóbal, S.A., Compañía Naviera San Ricardo, S.A., Huasteca Petroleum Company, Sinclair Pierce Oil Company, Mexican Sinclair Petroleum Corporation, Standford y Compañía Sucesores S. en C., Penn Mex Fuel Company, Richmond Petroleum Company de Mexico, California Standard Oil Company of Mexico, Compañía Petrolera El Agwi, S.A., Compañía de Gas y Combustible Imperio, Consolidated Oil Company of Mexico, Compañía Mexicana de Vapores San Antonio, S.A., Sabalo Transportation Compañy, Clarita, S.A. y Cacalilao, S.A., en cuento sean necesarios, a
} 
creó un discurso nacionalista con respecto de la explotación y administración del recurso petrolero, el cual rompió con la política porfirista de ceder amplia libertad a la inversión y privatización extranjera. Desde entonces, la frase de Justo Sierra de "colonización, brazos y capitales para explotar nuestra gran riqueza" (Zea, 1968, p. 313) se disolvió para dar paso a la retribución del pueblo mexicano, mediante una política que cerró las fronteras a la privatización extranjera de los bienes de la nación. Todo aquello que se encontrara dentro del territorio mexicano interesaba exclusivamente al Estado mexicano.

A pesar de que el territorio mexicano fue purgado de la monopolización extranjera desde 1938, el abastecimiento de petróleo nunca dejó de atenderse dentro del mercado mundial — en mayor o menor medida - . El gobierno porfirista creó las condiciones necesarias para la implementación de un aprendizaje industrial petrolero, cuya independencia llegaría con el triunfo del Estado revolucionario y la instauración institucional. Este aprendizaje se vio reflejado en la práctica de la industria petrolera por extensión, es decir, a partir de un sistema exploratorio que amplió las dimensiones petrolíferas del territorio mexicano con el seguimiento de un marco legislativo que protegió, incentivó y aceleró la producción petrolera.

\section{RÉGIMEN JURÍDICO Y DE PROPIEDAD: LOS CASOS DE las haCiendas Petroleras de Chapopote y El Álamo}

Para abordar el régimen de propiedad, así como el problema jurídico que experimentaron las haciendas petroleras en el norte del estado de Veracruz antes del decreto expropiatorio de 1938, es necesario tomar en cuenta algunas consideraciones acerca de la tenencia de la tierra y su relación con la legislación petrolera mexicana.

Según Ana María Serna, los cambios socioeconómicos producidos en las regiones petrolíferas del norte del estado de Veracruz fueron inherentes a la tierra. Ella parte de la idea de que cuando las compañías petroleras arribaron a la zona rural del norte de Veracruz, esta ya contaba con una estructura agraria operada por indígenas, arrendatarios y familias terratenientes. La estructura agraria estaba dividida en pueblos comunales, acciones individuales de condueñazgos y pueblos, ranchos y haciendas, las cuales no cambiaron su estatus a pesar del establecimiento de la industria privada del petróleo. Lo que sí se modificó fue la anatomía territorial, los

juicio de la Secretaría de la Economía Nacional para el descubrimiento, captación, conducción, al macenamiento, refinación y distribución de los productos de la industria petrolera” (Petróleos Mexicanos, 1988, pp. 28-29). 
hábitos y los tipos de relaciones sociales. Por ejemplo, para conectar las haciendas con el Golfo de México a fin de dar libre tránsito al petróleo hubo que utilizar espacios limítrofes; o bien, para no interrumpir las actividades agrícolas de las haciendas, las compañías solo arrendaron la parte extractiva, con lo cual la propiedad se convirtió en un híbrido económico (Serna, 2008, pp. 75-79).

Esta situación la explica Ana María Serna en función de las "continuidades sociales que prevalecieron del antiguo régimen hasta la década de los veinte". En primer lugar, las relaciones de poder generadas entre la clase media rural y las compañías petroleras imposibilitaron cualquier alianza entre la población y los gobiernos revolucionarios; en segundo lugar, no hubo una estabilidad política que permitiera una continuidad de la Constitución de 1917, y por último, el petróleo se convirtió en un producto de extrema importancia para los intereses económicos de la nación (Serna, 2008).

Dada su productividad y su cercanía al Golfo de México, el municipio de Temapache representó un punto estratégico para las actividades petroleras de las compañías extranjeras en el norte del estado de Veracruz. Su jurisdicción abarcaba propiedades particulares, en su mayoría, situación que favoreció a las compañías para realizar contratos de arrendamiento. Hasta el siglo XX, su extensión territorial era utilizada, en gran medida, para la agricultura, la ganadería y la explotación de maderas finas y para la construcción. Con la inclusión de la industria petrolera a las actividades económicas del municipio, se abrieron nuevos espacios que dieron forma a una jurisdicción industrial (Serna, 2008).

Con la introducción de la industria petrolera, las haciendas del municipio de Temapache pasaron a formar parte de un área extractiva que tuvo salida al exterior a través de oleoductos, ríos y caminos de paso de mula. El área estaba integrada por las haciendas petroleras de Buena Vista, Zapotal de Solís, Alazán, Potrero del Llano, Horcones, Tierra Blanca, Tierra Amarilla, Palma Real, Cuchilla de la Cal, Tumbadero, Cerro Viejo, Llano Grande, La Pita, Guadalupe, Las Cañas, La Estación, San Miguel, Agua Nacida, El Callejón, Tamatoco, Chapopote, Jardín, Molino, El Álamo, San Isidro y Paso Real; veintiséis puntos geográficos situados entre los municipios de Cerro Azul y Castillo de Teayo, que conjuntamente formaban el área petrolífera, la cual abarcaba casi la mitad de la Faja de Oro. De las haciendas mencionadas, Potrero del Llano, El Álamo y Chapopote figuraron como las más productivas hasta la década de 1920; estas dos últimas eran las mayormente reguladas por sus propietarios en cuanto a producción, instalación y explotación de recursos naturales. La prueba de ello fue que, en 1925, la familia 
Núñez demandó a la compañía Penn Mex Fuel Company por incumplimiento de contrato con respecto de la explotación de la hacienda El Álamo, y, más adelante, en 1928, interpuso una nueva demanda en contra de autoridades federales por el otorgamiento de permisos para explotar petróleo en la hacienda Chapopote.

De acuerdo con la documentación histórica que explica tanto el tipo de régimen de propiedad como el problema jurídico desarrollado en torno a la explotación y concesión de permisos de perforación referentes a las haciendas El Álamo y Chapopote, las fricciones que hubo entre la familia Núnez con respecto de la compañía Pen Mex Fuel Company y las autoridades federales se debió, en gran medida, a las consecuencias que trajo consigo la lucha por el control económico y administrativo del recurso petrolero. En palabras de Myrna Santiago, estas fricciones fueron producidas por complejas redes sociales que se tejieron alrededor de la industria, cambios en los patrones de uso y tenencia de la tierra, así como la configuración territorial de la industria petrolera. El problema jurídico y las fricciones desatadas en torno al régimen de propiedad estuvieron sujetos a cambios sociales y económicos drásticos, pues todo ocurrió en poco más de treinta años, mucho menos tiempo que requirió, por ejemplo, el establecimiento de la ganadería y el aprendizaje milenario de las sociedades indígenas acerca de la explotación comunal del ecosistema (Santiago, 2006, pp. 103-104).

El proceso jurídico y legislativo vinculado al control y administración del recurso petrolero se llevó a cabo en medio de una revolución que precipitó la toma de decisiones, sobre todo si tomamos en cuenta que en el municipio de Temapache predominaba la propiedad particular, cuyos dueños habían conformado un grupo de poder regional desde la segunda mitad del siglo XIX, el cual se apegó desde un principio a las leyes porfiristas para extraer petróleo de sus respectivas haciendas. Sin embargo, aunque las leyes porfiristas apoyaron, de alguna manera, a los propietarios particulares, la protección de sus intereses económicos y la posesión de la tierra estuvieron en juego durante el periodo revolucionario.

Esta situación se encuentra presente en las demandas que interpusieron los Núñez en contra de la compañía Penn Mex Fuel Company en 1925. Esta familia fue representada por sus apoderados legales Guillermo Rocha y Luis Cabrera, quienes desaprobaron en su momento aquello que llamaron "el efecto de la prosperidad petrolera”. De acuerdo con el sustento histórico de Guillermo Rocha y Luis Cabrera, los propietarios particulares, también llamados superficiarios, fueron los más afectados dados los obstáculos impuestos por el Ejecutivo, motivo que justificó su alianza con las compañías petroleras para defender sus derechos ante las leyes nacionalistas 
petroleras. El problema no radicó en el espíritu de las leyes de la Constitución de 1917, sino en la actitud asumida por los gobiernos revolucionarios y posrevolucionarios con respecto de los dueños de la tierra. Había, en efecto, un discurso nacionalista revolucionario, pero finalmente la realidad pendía de las leyes porfiristas que beneficiaban a las compañías petroleras, promovidas principalmente por el Ejecutivo. Esto se reflejó en varias ocasiones en la poca libertad que se les otorgó a los superficiarios para celebrar los contratos de explotación de petróleo, libertad que las compañías sí poseían para abrir pozos y computar regalías (AHP, fondo Expropiación, caja 653, expediente 17652, f. 35).

Guillermo Rocha decía que los superficiarios tuvieron serias dificultades para regular incluso sus contratos particulares, pues las compañías nunca ofrecieron cuentas reales de las cantidades de petróleo extraído, mucho menos de las regalías que debían proporcionar. Esta situación fue catalogada por Guillermo Rocha como un aspecto moral que había sido disfrazado por una justicia ciega como producto de un discurso construido y procurado con base en leyendas acerca de la riqueza petrolera, la inversión de capitales, la honradez, la solvencia, el interés público y el progreso nacional. Este discurso era como una tela invisible que envolvía la falta de conciencia para explotar el petróleo, el otorgamiento de amplios derechos a compañías sin escrúpulos, el regateo de las regalías y un ardid llamado progreso industrial.

Dicho discurso no representaba la realidad social de las regiones petroleras, pues estaban entregadas al despilfarro. La leyenda de la inversión de capitales, por ejemplo, hacía alusión a las operaciones de contrato de arrendamiento y perforación que estaban entregadas al "coyotaje". Para cada operación había un coyote específico, desde el que conseguía el contrato hasta el que obtenía el permiso de perforación. El segundo ingrediente era la especulación: si el pozo brotaba, entonces la propiedad valía "un millón de pesos de capital extranjero invertido", de los cuales "la parte esencial estaba representada por el contrato de explotación que se pagaría más tarde en forma de regalías al superficiario", que en la mayoría de los casos resultaba cualquier nimiedad (AHP, fondo Expropiación, caja 653, expediente 17652, f. 40). De igual manera, en la mayoría de las ocasiones en que se presentaron conflictos entre superficiarios y compañías petroleras, estas arguyeron en su defensa que habían "invertido en México cientos de millones de pesos, confiados en la protección que las leyes mexicanas deben conceder al capital extranjero; nosotros que hemos transformado a fuerza de trabajo regiones incultas del país dando empleo a sus habitantes y sembrando el bienestar en todos los hogares" (AHP, fondo Expropiación, caja 653, expediente 17652, ff. 42-43). 
Las compañías también utilizaron diversos mecanismos para operar holgadamente en las regiones petroleras de México. El artificio principal eran las llamadas compañías subsidiarias, es decir, empresas embrionarias de una gran matriz extranjera que estaba fuera de los alcances jurídicos de la Suprema Corte de Justicia de la Nación. Pocas veces los superficiarios sabían el valor del petróleo extraído mediante las subsidiarias, las cuales tenían como principal respaldo de inversión sus instalaciones, mientras que la matriz absorbía el verdadero valor comercial a través de operaciones directas de venta de crudo y productos refinados; a este proceso se le denominó leyenda de la solvencia. A la par se encontraba la leyenda del interés público, que mencionaba a las compañías como algo sagrado por el enorme interés y empeño en que estas extrajeran el petróleo, según lo que el gobierno mexicano entendía como riqueza nacional, concepción que concedía considerables ventajas a las compañías (AHP, fondo Expropiación, caja 653, expediente 17652, ff. 42-45).

La razón de ser de este fetichismo es que el renglón principal de nuestro presupuesto ha llegado a ser el ingreso por explotación de petróleo. Con el petróleo se pagan las decenas; con el petróleo se compran las armas; con el petróleo se pagan las facturas privilegiadas; con el petróleo, en fin, se espera cubrir los compromisos internacionales que nos dejó Don Adolfo de la Huerta. El petróleo es sagrado y iguay del que se atreva a tocar esa fuente de ingresos de nuestro Gobierno!

Una vez en este camino, no es ya de admirar que la Huasteca Petroleum Company con sólo prestar dinero al Gobierno Mexicano haya logrado que éste pase resueltamente por encima de todas las consideraciones de justicia hacia sus propios nacionales, y conceda a la omnipotente empresa del Sr. Doheny todo lo que éste pida en Juan Felipe en Cerro Azul (AHP, fondo Expropiación, caja 653, expediente 17652, ff. 44-45).

Por otro lado, en el caso de la leyenda del progreso nacional, se observaba que detrás de las obras filantrópicas de las compañías en las regiones petroleras y del proceso civilizatorio que se auguraba en el país con el desarrollo económico que generó la industria del petróleo había un falso discurso que cubría las discordias incentivadas por las compañías en el norte de la entidad veracruzana y los préstamos que garantizaban la libertad de acción. Por su parte, la leyenda del Rey Midas era muy representativa en cuanto a lo que significaba la riqueza petrolera mexicana, tal cual lo expresa la siguiente cita hecha por Guillermo Rocha: 
Su Majestad el Chapopote trae consigo la maldición de Baco; pero a diferencia del Rey Midas no la considera como maldición, sino como un don del que alardea y sigue usando ampliamente.

Su Majestad el Chapopote se enorgullece de su poder, y cada día es mayor la embriaguez de su triunfo. Todo lo convierte en oro. Toca las tierras y éstas se esterilizan para la agricultura, y sus ríos se hacen impotables, pero en cambio brota del suelo u chorro de oro negro; sólo que en vez de derramarse sobre la región, se encauza bien entubado hacia terminales para embarcarlo. Toca a los hombres, y cuando no mueren a su contacto, como Hilario Jacinto, Manuel Gómez o Joaquín Bermúdez, su corazón se cuaja en oro, y apoderándose de su voluntad los convierte en esclavos. Toca a las autoridades, y las convierte en becerros de la codicia: todo en fin se mancha de negro y se convierte en oro al contacto del nuevo Rey Midas (AHP, fondo Expropiación, caja 653, expediente 17652, ff. 47-48).

La metáfora de la "prosperidad petrolera", como pretexto jurídico para defender el derecho de propiedad y usufructo de la familia Núñez, fue el preámbulo de un alegato petrolero que ilustra las fricciones que hubo entre superficiarios, compañías petroleras y el emergente Estado revolucionario.

El primer caso que detectamos con respecto de las fricciones mencionadas se ubica en 1925. Para entonces, Guillermo y Jacinto Rocha y Manuel Núñez, cesionarios de Pilar, Arturo y Josefa Núñez, promovieron una demanda de embargue precautorio contra la compañía Penn Mex Fuel Company, con el fin de garantizar la demanda mercantil, que se llevó a cabo bajo concepto de providencia precautoria, ${ }^{7}$ la cual reclamaba la rescisión del contrato sobre explotación petrolífera con fecha de 20 de julio de 1912; la devolución material del lote El Álamo (perteneciente a la hacienda El Álamo), junto con mejoras y pozos (casa, vías, construcciones e instalaciones); el cumplimiento del pago de 3437100.34 dólares por concepto de diferencia en el volumen de petróleo (147290.61 pesos), diferencia de precio en el valor de petróleo (3 240909.28 pesos), y valor de diez por ciento de la gasolina explotada (48 900.45 pesos); el pago de intereses legales de las sumas reclamadas por concepto de regalías; el pago de 10000 pesos por el empleo de maderas para la construcción de casas, durmientes y postes, y el pago de las costas y gastos judiciales para hacer valer las reclamaciones (AHP, fondo Expropiación, caja 653, expediente 17652, ff. 51-52).

\footnotetext{
7 Medida preventiva para asegurar el buen resultado del juicio, el cual implicaba el embargo precautorio. Esto para prevenir que en todo caso de existir sentencia condenatoria esta pudiera ser ejecutada sobre los bienes del demandado para evitar que dilapidara u ocultara los bienes.
} 
El motivo de la demanda era que en el contrato colectivo de explotación del subsuelo de los terrenos de El Álamo, Jardín y El Molino, del excondueñazgo de Cicuaque, realizado entre la familia Núñez (Arturo, Pilar y Josefa) y la compañía Penn Mex Fuel Company, esta se comprometía a pagar una regalía de diez por ciento "de los productos brutos que explotara en el subsuelo". En el cumplimiento de sus obligaciones, la compañía realizó sus respectivos pagos con demasiada irregularidad a los propietarios. Al revisar la contabilidad, los señores Núñez se percataron de que la compañía había extraído cuarenta y tres millones de barriles de petróleo de los citados terrenos y nueve millones de litros de gasolina por compresión de vapores, cantidades que no eran proporcionales a las liquidaciones hechas a los propietarios. La compañía manejaba el precio de veintidós centavos, oro americano, por término medio, cuando en realidad su verdadero valor era de tres dólares con cincuenta centavos durante el periodo de la Primera Guerra Mundial. Haciendo cuentas, resulta que, al menos a la señora Josefa Núñez de Llorente, la compañía le debía seis millones de pesos (AHP, fondo Expropiación, caja 653, expediente 17652, ff. 139-140).

La parte quejosa argumentaba que la compañía petrolera demandada no tenía arraigo en la República y que carecía de bienes en el país; “y por lo que hace a los bienes sobre los que se ejercía acción real, principalmente el petróleo extraído, por el temor fundado de que fueran dilapidados", debido a que el total producido era exportado al exterior para su venta. En ese sentido, la demanda en contra de la Penn Mex Fuel Company se hizo a partir de dos formas: acción real y acción personal. La acción real aludía al incumplimiento de las obligaciones con respecto de la producción de petróleo, cuyo producto quedaba fuera del alcance de cualquier orden de embargo, pues la mayoría era embarcada y remitida fuera del país, o bien vendida a la compañía El Águila. Según datos proporcionados por los libros confiscados de la compañía demandada, la producción media mensual extraída de los pozos era de 80 mil barriles, con precio aproximado de 80 mil dólares al mes, que sumado por el total de los meses demandados daba como resultado tres millones y medio de dólares. En tanto que la acción personal "garantizaba el resultado de la demanda en el momento de ser requerida de pago", teniendo en cuenta que "el embargo de la empresa de explotación y transporte de petróleo, en caso de llevarse a cabo, tendría que ser hecho bajo la forma de intervención" (AHP, fondo Expropiación, caja 653, expediente 17652, ff. 51-56).

Después de haber procedido al embargo de bienes para responder a la cantidad de ocho millones de pesos, oro nacional, el representante de la Penn Mex Fuel 
Company, el señor M. B. Koppe, pidió la suspensión de la providencia precautoria, argumentando lo siguiente:

Con la resolución atentatoria dictada por el Juez de Distrito de Túxpam que tiene todas las características de una expropiación, de una confiscación, se violan, en perjuicio de la "Penn. Mex. Fuel Company”, los artículos 14, 16,22 y 27 Constitucionales por los conceptos que se puntualizan en los capítulos anteriores y se causan a la quejosa un perjuicio de carácter irreparable, pues los actos de que se queja mi representada se ejecutan de momento a momento, como son del llamado interventor, que no ha prestado garantía ninguna; con las informaciones que el mismo sigue, obteniendo de los libros, papeles, y secretos de la empresa, actos todos ellos ejecutándose como queda expresado de momento a momento, cada vez que se llevan a cabo ponen a la Compañía quejosa en la situación de que no pueda restituírsele en el ejercicio de las garantías violadas, toda vez que por una parte las informaciones que, repito, obtiene de momento a momento el interventor, de los libros, papeles, y secretos industriales, entran en su patrimonio y son divulgadas causándose un daño totalmente irreparable.

Es indudable que las leyes que garantizan el sigilo y el respeto de la correspondencia y a los secretos industriales y comerciales, quedarían violados de una manera definitiva, absoluta y como expresay claramente lo determina el artículo 54 de la Ley de Amparo, en su fracción II, sería físicamente imposible poner al quejoso en el goce de las garantías individuales violadas. ${ }^{8}$

En la demanda de amparo presentada por la compañía Penn Mex Fuel Company, M. B. Koppe exponía que, de acuerdo con el señalado artículo 1172 del Código de Comercio, con base en el cual solicitaron providencia precautoria, tenía como principal apoyo los contratos de 1912 y 1924, en los que manifestaban los propietarios cerciorarse de que "la parte del producto que se le estaba pagando era el que verdaderamente le correspondía”, por lo tanto, eran a ellos a quienes les pertenecía el derecho de revisar libros del concesionario "cuando lo juzgare conveniente pero sin interrumpir o entorpecer los trabajos de éste”. Esto quiere decir que la inspección de libros era de individual y particular participación, rechazando cualquier posibilidad de involucramiento de personas por derecho de cesión. Esta era una infracción al

8 Las inconformidades están dirigidas al interventor José Domingo Lavín (particular con responsabilidades propias y que representaba los intereses particulares del actor) después de haber tomado posesión de los libros, talonarios, cheques y demás documentos. El ejercicio de sus funciones procedió después de que, en compañía del señor Guillermo A. Rocha, dio fe al levantamiento de sellos y de libros de contabilidad en las oficinas de la Penn Mex Fuel Company. Las cajas fuertes contenían auxiliares de cuentas y de ferrocarriles; inventarios y balances; libros mayores autorizados por el Timbre; libros de embarcaciones, producción de petróleo, construcciones y movimientos bancarios (AHP, fondo Expropiación, caja 653, exp. 17652, ff. 16 y 17). 
artículo 1173 del Código de Comercio y al artículo 14 constitucional que decía que nadie podía ser privado de sus posesiones y derechos, "sino mediante juicio seguido ante los Tribunales previamente establecidos", en el que se cumplieran las formalidades esenciales del procedimiento y conforme a las leyes expedidas con anterioridad al hecho (AHP, fondo Expropiación, caja 653, expediente 17652, ff. 119-121).

Después de que el juez de Distrito Numerario de Veracruz concedió la suspensión de oficio (orden de suspensión de actividades por posible afectación a situaciones de interés social) por encontrarse inaplicable el artículo 22 constitucional, la parte demandante expuso que la providencia precautoria se trataba de la intervención de una negociación industrial, decretada conforme a la ley, más no de una imposición de pena, expropiación o aplicación del fisco a bienes, tal como apuntaba el dictamen por el que se decretó la suspensión de oficio. Confiscar suponía la privación de bienes por parte de la autoridad y la aplicación por concepto de fisco, acepción que tenía por objeto "servir de pretexto a la suspensión de oficio, creado por la Penn Mex Fuel Company y aceptado con deliberada credulidad por el Juez". La suspensión era improcedente dado que los actos no causaban perjuicios de difícil reparación; es decir, la quejosa "tenía medios legales para que no se llevara adelante o continuara ejecutando la precautoria, tanto porque podía reclamarla, cuanto porque podía hacer uso del derecho" que concedía el artículo 180 de Código de Comercio, "pudiendo obtener levantamiento de la precautoria otorgando fianza bastante o demostrando tener bienes raíces con que responder del éxito de la demanda".

El asunto causó inquietud, incluso entre el mismo gremio de litigantes. En respuesta a la carta enviada por Luis Cabrera a Aquiles Elorduy en 1927, este contestó — por medio de otra carta — que no había intriga más grande que aprovechar la muerte del licenciado Guillermo Rocha para decir que había sido obra de un

\footnotetext{
9 La parte demandante pedía la revocación de la suspensión de oficio concedida por el juez por las siguientes razones: " 1 . Porque no se trataba de un caso comprendido por el artículo 22 Constitucional; $2^{\circ}$. Porque no había imposibilidad física de reponer a la quejosa en el goce de las garantías que decía violadas; $3^{\circ}$. Porque la simple posibilidad de abusos del Interventor en sus funciones no era motivo de amparo, ni tocaba a la autoridad federal prevenirlos o corregirlos, sino al Juez de los autos; $4^{\circ}$. Porque el acto estaba ejecutado y consumado; $5^{\circ}$. Porque el acto reclamado no era de tracto sucesivo momentáneo en cuanto se refería a la autoridad y no debían confundirse los actos de éste con los del interventor, que no era autoridad ni parte en el amparo; $6^{\circ}$. Porque la fianza mediante la cual se llevaba adelante la precautoria garantizaba los perjuicios que pudieran causarse al quejoso, y por tanto desde el punto de vista constitucional el acto no causaba perjuicios. [...] $8^{\circ}$. Porque los perjuicios que pudieran causarse no eran de difícil reparación, ya que existían medios legales para reclamar la precautoria y para obtener el levantamiento de que se haya decretado; $9^{\circ}$. Porque siendo notoriamente improcedente la demanda, debió haberse desechado sin conceder la suspensión, y ésta a su vez era improcedente; $10^{\circ}$. Porque estaba pendiente un recurso que tenía por objeto la revocación de la misma providencia precautoria que era el acto reclamado"(AHP, fondo Expropiación, caja 653, exp. 17652, ff. 20-30).
} 
asesinato provocado por los agentes de la Penn Mex Fuel Company, cuando ya se había comprobado que su homicidio se debió a una "tragedia de cabaret". La pretensión de Luis Cabrera de que Elorduy, como agente internacional y consejero de las compañías petroleras, rectificara la idea propalada ante el Ejecutivo de que los ministros de la Suprema Corte tenían precio era algo absurdo desde el punto de vista de Elorduy (AHP, fondo Expropiación, caja 3829, expediente 92198, f. 14), quien expresó a Luis Cabrera que:

Desgraciadamente, al tratarse del caso Penn Mex, tú eres el primero que, en tu afán de crear una mala atmósfera contra la compañía, y en general contra las compañías, has dicho en varias ocasiones que el oro de la Penn Mex ha tratado de comprar a la Justicia, cosas que, entre nos, poco habrá tenido cuando desde hace dos años y medio todas las resoluciones le han sido adversas y no ha podido lograr que se le devuelva su negociación, mientras que Rocha y Núñez han tenido éxito constantemente obteniendo aun resoluciones que, como la del Juez Cayetano Masse, fue revocada por unanimidad de votos en la Suprema Corte (AHP, fondo Expropiación, caja 3829, expediente 92198, f. 8).

En un comunicado que hizo Luis N. Morones a la Suprema Corte de Justicia de la Nación, en representación del Ejecutivo, afirmó que este estaba enterado de la situación acerca del juicio promovido por los señores Núñez y Rocha en contra de la compañía Penn Mex Fuel Company. Morones manifestaba que antes de que se promoviera dicho juicio, el presidente Plutarco Elías Calles había tenido una reunión privada con el representante de la Suprema Corte, el licenciado Manuel Padilla, en la cual el representante del Ejecutivo comentó que "por ninguna manera, la situación política e internacional del país podría fallarse en contrario a la compañía demandada”. De igual manera, Morones dijo que, después de una nueva consignación, los señores Arturo Núñez y Guillermo Rocha propusieron que se vendiera a la Administración de Petróleo Nacional el petróleo almacenado en los tanques de acero y las presas de tierra con que contaba la Penn Mex Fuel Company. Esta medida era indispensable porque, en caso de que no se vendiera en último momento a una compañía exportadora, podía pasar lo mismo que al general Manuel Peláez, a quien se le otorgó una concesión en 1922 para explotar el lote 19 de Zacamixtle, cuya producción, al no encontrar comprador, fue rematada a 20 centavos, oro americano, después de que el pozo había arrojado una producción de 40000 barriles diarios, secándose en lo sucesivo (AHP, fondo Expropiación, caja 3829, expediente 92198, ff. 25-27). 
Tras varios análisis, la Secretaría de Industria, Comercio y Trabajo acordó que se tratara de evitar el cierre de las válvulas — como lo había propuesto la Penn Mex Fuel Company - ante la preocupación de un posible agrietamiento del yacimiento, la fuga de aceite, el agotamiento de los pozos y hasta la pérdida de vidas humanas. Si esto ocurría, el erario nacional dejaría de percibir impuestos.

Posteriormente, la Secretaría procedió a investigar más a fondo el caso enviando técnicos en petróleo para inspeccionar la zona a fin de determinar si en realidad el manto de donde provenía el petróleo en el campo de El Álamo alimentaba también los pozos perforados en Chapopote y Tierra Blanca; si la invasión de agua salada había esterilizado los pozos; si el campo podía volver a producir cantidades costeables de petróleo, y si la producción era distinta a la manejada por la compañía Penn Mex Fuel Company (AHP, fondo Expropiación, caja 3829, expediente 92198, ff. 34-42). Apegada al dictamen final, la Secretaría de Industria, Comercio y Trabajo dictó dos acuerdos:

Los acuerdos de referencia, consisten, en primer lugar, en la orden expedida al Control de Administración de Petróleo Nacional, para que se encargue de la venta de los productos que la Penn Mex Fuel Co. tiene almacenada en su terminal Álvarez, del puerto de Tuxpan, a fin de que desaparezca el pretexto en que se apoya la mencionada empresa para demorar la explotación de los que tiene en la zona sur de Tuxpan; y el segundo, se relaciona con la consignación ante el Procurador General de Justicia de la Nación, de aquellos miembros del personal de la Penn Mex Fuel Co. Que resulten responsables de cierta maniobra encaminada a arruinar el yacimiento petrolífero, con perjuicio de los intereses del Fisco y de los participantes en el producto de los mismos (Excélsior, 1927).

A pesar de la resolución final de la Secretaría de Industria, Comercio y Trabajo, la operatividad de la Penn Mex Fuel Company se consideraba necesaria, pues dicha compañía contaba con un plan comercial que venía funcionando desde 1914. El hecho de limitar la capacidad de la compañía extranjera para regular su propia explotación implicaba obstaculizar la salida del petróleo hacia el exterior, operación que resultaba necesaria para generar el capital que regularmente era distribuido entre la mano de obra, los dueños de la tierra y el Ejecutivo. Ni las autoridades ni el Ejecutivo contaban con el mencionado plan comercial para destinar el petróleo extraído al mercado internacional. Sin embargo, esto no impidió que la familia Núñez continuara regulando las actividades extractivas y el cumplimiento de los acuerdos estipulados en los contratos de arrendamiento y de regalías computadas 
por el valor del petróleo extraído, situación que determinó su posición como propietarios afectados por desapego al contrato que firmó con la compañía Penn Mex Fuel Company, cuya demanda por embargue precautorio terminaron por ganar.

Sin embargo, la lucha por la defensa y usufructo de la tierra no cesó con el litigio ganado a la compañía norteamericana Penn Mex Fuel; por el contrario, continuó. El segundo caso registrado por la familia Núñez a favor de la defensa de su propiedad y sus intereses económicos inició en 1928. En este caso, Josefa Núñez de Llorente solicitó un amparo a las autoridades federales por otorgamiento equívoco de permiso para la perforación de un pozo llamado "Nacionales no. 172", que la Secretaría de Industria, Comercio y Trabajo y la Agencia de Petróleo en Tampico habían cedido para iniciar trabajos en la margen izquierda del río Pantepec, dentro de lo que dichas instituciones consideraban zona federal, en la hacienda de Chapopote, en el municipio de Temapache.

El amparo solicitado fundamentaba que la hacienda denominada Chapopote se encontraba en posesión de la familia Núñez desde 1828, ejerciendo sus derechos al subsuelo desde que comenzaron los trabajos de explotación petrolera a inicios del siglo XX bajo contrato de arrendamiento celebrado con la Tuxpam Petroleum Company antes de la promulgación de la Carta Magna. Hacia 1909, las leyes porfiristas le otorgaban las facultades para obtener la concesión confirmatoria para ejercer su derecho al subsuelo. Este otorgamiento reconocía el río Pantepec como lindero por la parte sur. Sin embargo, las especificaciones referidas fueron desconocidas por la Secretaría de Industria, Comercio y Trabajo, denominando la margen izquierda de la corriente del citado río como zona federal para explotar el pozo "Nacionales no. 172" (AHP, fondo Expropiación, caja 2653, expediente 70538, ff. 127).

La ocupación de la zona federal que promovió la Dirección de Control de Administración de Petróleo Nacional para explotar el pozo Nacionales no. 172 no tenía justificación porque la parte señalada era propiedad privada. La justificación de esta privación, contemplada en los artículos 14 y 16 constitucionales, violaba los derechos del propietario.

Históricamente, la hacienda Chapopote nunca fue considerada propiedad pública, incluyendo la ribera del río Pantepec. La Real Orden de 10 de septiembre de 1815 declaraba "a favor de los matriculados el libre uso de las costas y playas", esto se entendía literalmente como "todo aquel espacio que baña el agua del mar en su flujo y reflujo diario, y veinte varas comunes más arriba de la mar”. Incluso, hasta la Constitución de 1857, el gobierno nunca expidió una declaratoria que indicara 
que las zonas contiguas a las riberas de los ríos fueran propiedad de la nación; por el contrario, se "instituyó la propiedad privada como una garantía individual" (AHP, fondo Expropiación, caja 2653, expediente 70538, f. 129), asimismo la fracción XXXIII del artículo $2^{\circ}$ declaraba como bienes generales "los bosques y parques [...] las islas y playas, los puertos, radas, ensenadas, bahías, vados, ríos, lagunas y caídas de agua, sin perjuicio de observarse las leyes vigentes, respecto al uso que a los particulares les está permitido hacer de esos bienes" (AHP, fondo Expropiación, caja 2653, expediente 70538, f. 131).

Posteriormente, el Código Civil de 1884 ratificaba el reconocimiento de los derechos de los dueños de la propiedad privada sobre los terrenos ribereños de los ríos, reglamentación que había sido emitida desde las leyes de 1868 y 1870, respectivamente, las cuales enumeraban los conceptos de bienes de dominio público, y no incluían los mencionados terrenos ribereños.

A finales del XIX, el gobierno de Porfirio Díaz dictó disposiciones en las leyes de 1888, 1893 y 1894 en las que reglamentaba la declaratoria de las vías generales de comunicación, como ríos interiores, flotables o navegables y aquellos de cualquier clase que sirviesen de límite a la República o a dos o más estados; el señalamiento de lugares en que "los terrenos contiguos a los ríos tuvieran el carácter de baldíos”; el nulo establecimiento de ningún precepto de propiedad a favor de la nación, y la relación del dominio de la federación con la prohibición y la enajenación de las riberas de los ríos navegables, reglamentación que volvió a aparecer en las leyes del 31 de octubre de 1901, la de Bienes Inmuebles de la Federación del 18 de diciembre de 1902 y la Ley del 20 de junio de 1908. Todavía en 1910 se implementaron reformas a través de la Ley de Aguas, cuyo artículo 10 especificaba que las tierras ribereñas eran todas aquellas que lindaban con los cauces y lechos de las aguas de territorio federal (AHP, fondo Expropiación, caja 1653, expediente 70538, f. 131).

En relación con las disposiciones dictadas por las leyes, el artículo 27 constitucional de 1917 establecía la garantía de la propiedad privada "sin más límite que el de la ocupación”, mientras que el artículo 14 especificaba la garantía de la no retroactividad de la ley, y el artículo 16, la garantía de la intangibilidad de la posesión, "a menos que hubiera en contra un mandamiento escrito de autoridad competente en que se aplicara con exactitud la ley del caso" (AHP, fondo Expropiación, caja 2653, expediente 70538, f. 130). De acuerdo con lo expuesto por la propietaria, Josefa Núñez de Llorente, la aplicación del artículo 125 era también controversial: 
Finalmente, el artículo 125 fué el único en que nuestros constituyentes quisieron referirse a los bienes que después se han llamado de la propiedad de la Nación. Pero salta a la vista que nuestros constituyentes, como un concepto más propio aunque incompleto, de lo que después se ha venido a llamar propiedad de la Nación y se ha equiparado exageradamente a la propiedad privada (como si el Estado tuviera la libre disposición de esas pretendidas propiedades y no estuviera sujeto su uso o aprovechamiento a leyes obligatorias para el mismo Estado), nuestros constituyentes, digo, reconocieron que una propiedad pública, una propiedad del Estado, en realidad no sólo es propiedad sino que es el concepto antagónico de la propiedad; y por lo mismo sólo establecieron para el Gobierno el de derecho de inspeccionar o vigilar esallamada propiedad pública (AHP, fondo Expropiación, caja 2653, expediente 70538 , f. 130).

Para efectos de la explotación petrolera, las leyes de 1892 y 1909 facultaban al dueño del suelo para explotar combustibles y minerales, además de declarar el suelo, junto con criaderos y depósitos, como exclusiva propiedad del dueño. Aunque el artículo 27 de la Constitución de 1917 sí declaraba el petróleo e hidrógenos como dominio directo de la nación, la ley no podía aplicar dado que la Suprema Corte ya había establecido jurisprudencia antes de la promulgación de la Carta Magna. Esta razón iba en contra de la disposición del departamento de Control de Administración de Petróleo Nacional de explotar el pozo Nacionales no. 172, debido a que la declaratoria se sujetaba al exclusivo precepto de propiedad nacional respecto del petróleo del subsuelo, siendo que la expropiación para utilidad pública sin una previa indemnización, tal como lo indicaba el mismo artículo 27, no tenía aplicación. A pesar de que el juicio terminó a favor de la familia Núñez, la defensa de sus propiedades petroleras se prolongó años más tarde.

Por lo que respecta a la hacienda El Álamo, según los juicios de amparo acumulados de 1937 promovidos por Josefa Núñez de Llorente y la compañía Penn Mex Fuel Company contra actos de algunos funcionarios (secretario de Agricultura y Fomento, secretario de Economía Nacional y director de Población Rural, Terrenos Nacionales y Colonización) por errónea demarcación de zona federal del río Pantepec, corriente que lindaba con la hacienda El Álamo, se reclamaba la violación territorial que comprendía la margen izquierda de la corriente del río Pantepec, sitio donde se ubicaban los pozos Álamo números 1, 7, 14 y 37, los cuales se encontraban en actividad bajo explotación de la Penn Mex Fuel Company. El argumento de inconformidad expuesto por la propietaria, Josefa Núñez, y la compañía Penn Mex era que, según el informe presentado por el secretario de Agricultura y Fomento, 
los pozos mencionados se encontraban dentro de una demarcación administrativa que correspondía a la propiedad de la nación.

De acuerdo con las respuestas presentadas por los peritos encargados de contestar el cuestionario elaborado por la Secretaría de Agricultura y Fomento con fecha 14 de agosto de 1937, el río Pantepec había sido declarado propiedad de la nación por decreto de 6 de octubre de 1920, en tanto que los pozos 1, 7, 14 y 37 se encontraban dentro del cauce mayor del río, en la margen derecha de este, y según lo definido como zona federal en la Ley de Aguas de la Propiedad de la Nación, dichos pozos se hallaban fuera de la jurisdicción que comprendía la faja de 10 metros de anchura contigua al cauce de la corriente, por ende, la margen no podía considerarse propiedad de la nación (AHP, fondo Expropiación, caja 2455, expediente 67115, f. 29$)$.

En el amparo que solicitó la señora Josefa Núñez de Llorente por la violación y perjuicio de las garantías asentadas en los artículos 14 y 16 de la Constitución Federal, la propietaria reprobaba la señalización de la demarcación de la zona federal tomando como base la margen izquierda de la corriente adyacente a la hacienda El Álamo, para lo cual se remitió a una serie de pruebas para refutar la inexacta aplicación de la fracción IV del artículo $4^{\circ}$ del Reglamento de la Ley de Aguas vigente.

De principio, la propietaria comprobó que en realidad era dueña de dicha hacienda, en la cual se llevaron a cabo trabajos de exploración y explotación petrolera poco después de 1912, año en que firmó el contrato de arrendamiento con la compañía Penn Mex Fuel Company, con lo que justificaba que ejerció su derecho al subsuelo antes de la Constitución de 1917, gracias a la concesión confirmatoria que le otorgó la Secretaría de Industria, Comercio y Trabajo. Estas pruebas evidenciaron una violación de los artículos 14 y 16 constitucionales, que indicaban que "nadie podía ser molestado en sus propiedades", mucho menos privados de estas a menos que existiera un juicio previamente establecido mediante protocolización del Tribunal (AHP, fondo Expropiación, caja 2455, expediente 67115, ff. 137-138).

La violación de las garantías plasmadas en los artículos 14 y 16 tenía como uno de sus principales referentes la fracción IV del artículo 122 de la Ley de Aguas de 1934, que especificaba que:

Se entiende por cauce de una corriente, el canal que tiene la capacidad necesaria para que escurran las aguas de las mayores crecientes ordinarias, pero en las corrientes o en las partes de las mismas sujetas a desbordamientos,y mientras no se construyan obras de encauzamiento o canalización, el cauce estará constituido por el canal naturalmente cavado por las aguas 
de la corriente, o por el formado por el sistema general de obras de defensa (AHP, fondo Expropiación, caja 2455, expediente 67115, f. 139).

El reclamo de violación de los artículos 14 y 16 tenía como fundamento el ejercicio del poder Ejecutivo, del que mencionaba que podía expedir disposiciones solo como medio práctico que diera exacta observancia de la ley, mas nunca el derecho de modificar el contenido de las reglamentaciones. La ley de 1934 carecía de validez porque la fracción IV era inaplicable a lo que se entendía como "corriente" y "faja" según la Ley de Aguas vigente; de igual manera, el concepto de zona federal no podía proceder porque los pozos 1, 7, 14 y 37 no se encontraban dentro del margen que especificaba las leyes reglamentarias.

En coincidencia, durante el tiempo en que la propietaria Josefa Núñez solicitó amparo ante las autoridades federales, la Secretaría de Comunicaciones y Obras Públicas, en representación del Ejecutivo de la Unión, celebró con la compañía El Águila contratos de arrendamiento de terrenos ubicados en ambas márgenes del río Pantepec, considerados zona federal, en específico en el Estero de Tampachoco, con el fin de tender una tubería para el bombeo del campo de El Álamo. La zona federal destinada para la ocupación se hallaba en terreno particular, dentro del perímetro que la Penn Mex Fuel Company exploraba bajo contrato de arrendamiento con la señora Josefa Núñez de Llorente. Ante esta situación, la Penn Mex Fuel Company, a través de su apoderado, el señor John M. Peardon, mostró su inconformidad a la Agencia de Petróleo:

Como apoderado de Penn Mex Fuel Company, personalidad tengo debidamente acreditada Agencia de Petróleo Tampico, hago ante usted más respetuosa pero enérgica protesta contra cualquier tramitación de solicitudes permisos para perforación pedidosfecha diez diciembre por Control Petróleo Nacional en zona federal de Hacienda Alamo, Municipio Temapache, Cantón Tuxpam, Estado de Veracruz, que según entiendo cubren pozos ciento sesenta y uno, ciento sesenta y tres, ciento sesenta y siete, ciento sesenta y ocho y ciento setenta y uno, registrados Agencia de Tampico bajo números quinientos treinta y cuatro, ochocientos noventa y uno, al quinientos treinta y cuatro ochocientos noventa cinco inclusive. Fundo mi protesta primero por contrato de veinte de julio de mil novecientos doce por cual mi representada arrendó el subsuelo petrolifero hasta del río Túxpam y no hasta margen zona federal; segundo en que el único derecho que tiene o pudiera tener el Gobierno Federal en las fajas que comprende zona federal es un derecho de servidumbre para el libre paso público trabajos ribera y diques; tercero en que derechos mi representada están amparados 
por concesión número siete dos uno. Uno (tres, tres, uno-cuatro) cuatrocientos diezy ocho, y hasta niéguese concesión aludida no puedese privar mi representada derecho preconstitucionales (AHP, fondo Expropiación, caja 2653, expediente 70543, f. 2).

Las autoridades federales no lograron intervenir en la exploración y explotación de la hacienda Chapopote por lo menos durante dos años, a pesar de que la Constitución de 1917 los facultaba para iniciar el proceso de demarcación de zonas nacionales para administrar la producción petrolera. Este proceso tuvo su desenlace después de la aplicación de la ley expropiatoria de 1938 y del impulso de la política agraria, la cual fragmentaría las haciendas petroleras, fenómeno que no trataremos en el presente artículo, pues atañe a otro tipo de análisis.

La documentación correspondiente a las haciendas El Álamo y Chapopote evidencia tres cosas. En primer lugar, como pocos casos ocurridos en México, la familia Núñez buscó asegurar tanto los bienes como los beneficios económicos de la industria petrolera a través de un procedimiento jurídico, el cual exhibió las limitaciones legislativas de un Estado mexicano en transición, así como las contradicciones de los contratos particulares de arrendamiento, exploración y explotación. En segundo lugar, se produjo una disputa por territorio encabezada por instituciones que representaban al Ejecutivo en contra de la superficiaria Josefa Núñez de Llorente debido a que la nacionalización de la tierra y del petróleo implicaba la conversión de propiedad privada a zona federal. Por último, hace patente el interés del Ejecutivo por encargarse de la administración directa de la explotación del subsuelo con el respaldo que le pudiera otorgar la Carta Magna, pero en el camino se encontró con un grupo de superficiarios (la familia Núñez) que hicieron todo lo posible por defender su derecho al subsuelo. Estos desacuerdos complicaron el ejercicio de las instituciones con que el Ejecutivo dispuso para aplicar la Constitución de 1917. También queda de manifiesto que hubo diversos intereses nacionales y regionales por controlar la extracción del aceite mineral y los hidrocarburos, lo cual imposibilitó la eficiente implementación del artículo 27.

El caso particular de las haciendas de El Álamo y Chapopote ejemplifica perfectamente las complicaciones del libre ejercicio de las autoridades federales bajo respaldo de la Constitución de 1917. Por encima de los preceptos de la Carta Magna y de los intereses del Ejecutivo por controlar la explotación petrolera estaba el reconocimiento de la familia Núñez como los legítimos dueños de la tierra y, por tal motivo, del petróleo. La estricta aplicación de la ley tenía sus propias contradicciones, sobre todo si tomamos en cuenta que, aunque ya existían preceptos 
constitucionalistas, el espíritu de estos era transitorio ante el ejercicio de gobiernos efímeros, constantes cambios políticos y una situación social y económica delicada. Basta recordar que entre 1920 y 1934 aconteció la rebelión delahuertista, Obregón fue asesinado por el religioso León Toral, se desarrolló el conflicto religioso de la Cristiada y Plutarco Elías Calles impuso el Maximato, por mencionar algunos acontecimientos. Paralelamente, el estado de Veracruz se enfrascó en una serie de conflictos entre campesinos y hacendados después de que el gobierno de Adalberto Tejeda (1920-1924 y 1928-1932), a través de la Liga de Comunidades del Estado de Veracruz, incentivó la formación de comités agrarios para facilitar las dotaciones ejidales de campesinos que había por toda la entidad veracruzana. ${ }^{10}$

Sin embargo, tal como nos muestra la documentación histórica de las haciendas El Álamo y Chapopote, ni el gobierno revolucionario tuvo el control de la riqueza petrolera y la administración territorial, ni la Constitución de 1917 fue acatada al pie de la letra. Por el contrario, con pocos obstáculos, las compañías extranjeras continuaron explotando los campos petroleros, mientras que los superficiarios que habían consolidado una estructura de poder desde la segunda mitad del siglo XIX se mantuvieron apegados a las ventajas que las leyes porfiristas habían otorgado. Pero, por otro lado, aunque las compañías tuvieron determinadas libertades de posesión territorial, extracción petrolera y distribución comercial, tuvieron que enfrentarse a la capacidad negociadora de las familias propietarias, las cuales se sujetaron a las condiciones económicas que los contratos les otorgaron en toda la extensión de la palabra.

Los primeros contratos de arrendamiento estaban respaldados por las leyes porfiristas, las cuales beneficiaban tanto a las compañías como a las familias que se hallaban en calidad de superficiarios; es decir, se privilegiaba a la propiedad privada

${ }^{10}$ La Ley de 6 de enero y el artículo 27 constitucional cobraron fuerza en la entidad veracruzana durante el primer periodo gubernamental de Adalberto Tejeda (1920-1924) a causa de la comunión de dos factores: la apertura de posibilidades para solicitar restitución y dotación de ejidos por parte de aquellos pueblos alterados por la enajenación de tierras, y la disponibilidad del gobierno para crear líneas políticas de acción popular para concentrar obreros y campesinos como consecuencia de un sistema político organizado. Esto significaba una alianza con los agraristas y una movilización y concentración de los trabajadores.

Con la creación de la Liga de Comunidades Agrarias del Estado de Veracruz (LCAEV) el 23 de marzo de 1923, los trabajadores del campo, agrupados para ese entonces alrededor de sus núcleos de población, encontraron una organización que les dio mayores posibilidades de enfrentar conjuntamente a los terratenientes.

En la Huasteca veracruzana, las solicitudes ejidales y la formación de comités agrarios no se hicieron esperar. En el municipio de Temapache se crearon comités en casi todas sus poblaciones a partir de 1921 con el apoyo de la Agrupación de Arrendatarios de Álamo y la Comisión Agraria Mixta. Esta situación perjudicó a la industria petrolera y a los hacendados de lazona. Los poblados que inicialmente formaron su Comité Ejecutivo Particular fueron Temapache, Raudal, Raya Oscura, Puerta Reforma, Palo Blanco, El Jardín, El Molino, La Estación, Paso Real, La Noria y Álamo (Meyer, 1978, p. 79; Velasco, 1993, p. 77; Fowler, 1979, p. 40; AGEV, fondo Almanza, caja 3, expediente 78). 
y a la inversión extranjera. Los convenios de explotación petrolera respaldaron el trabajo de las compañías, pues evitaron pagar mayores impuestos al Estado y, en vez de esto, acordaron pagar a las familias regalías estipuladas en los contratos de arrendamiento, las cuales fueron irregulares.

\section{Conclusiones}

Observamos, mediante los documentos, un diálogo jurídico en el cual aparecen actores sociales que intervinieron en el proceso de construcción del Estado nacional. Si bien es cierto que el régimen revolucionario fue transitorio e inestable, motivo por el cual la Constitución de 1917 tuvo una difícil aplicación, esto no quiere decir que los sucesores de Venustiano Carranza no hayan querido controlar y administrar la riqueza petrolera nacional.

En la relación entre el régimen revolucionario y las compañías petroleras participaron departamentos petroleros nacionales, gremio de abogados, instituciones jurídicas y superficiarios. Estos actores ayudaron a que el conocimiento de la industria petrolera fuera más profundo, pues el petróleo no solo fue visto como una sustancia industrialmente manipulable y generadora de riqueza económica, sino también como un producto inherente a un marco legislativo, relaciones de poder, así como uso y tenencia de la tierra. La industria petrolera era multidimensional y como tal debía ser tratada.

Aunque las leyes porfiristas fueron el principal instrumento jurídico para que tanto compañías petroleras como superficiarios operaran bajo el concepto de propiedad privada, lo que nos muestra la faceta política revolucionaria es que fue todo menos pasiva. La muestra de ello es que los gobiernos mantuvieron contacto con las actividades petroleras mediante la supervisión, inspección y evaluación de los procesos industriales del petróleo. Lo mismo podemos decir de los superficiarios, pues los documentos jurídicos demuestran que el vínculo económico generado con las compañías petroleras no solo se forjó en función de mantener un poder local-regional ante la intervención del Estado revolucionario, sino también fue cambiante y ríspido.

A pesar de que las fricciones jurídicas y los desacuerdos económicos fueron una constante en el proceso industrial petrolero, hubo una relación intermitente entre Estado, compañías y superficiarios, la cual fue determinante en la construcción de un territorio petrolero repleto de complejidades sociales en el norte del estado de Veracruz. 
En las demandas llevadas a cabo por la familia Núñez queda claro que las compañías sí causaron drásticos cambios y afectaciones, pero esto fue en mayor proporción por la libertad que tuvieron para operar mediante la infraestructura extractiva y comercial en tierra de superficiarios sin regulación constitucional. ¿Por qué esta forma tan peculiar de operar? No había seguridad nacional y administración territorial que limitaran la capacidad de las compañías para extraer, comerciar y hacer uso del petróleo; el Estado revolucionario necesitaba las entradas al erario nacional que los impuestos petroleros recaudaban; los superficiarios tenían una relación directa con la tierra; la Suprema Corte de Justicia no tenía la capacidad para intervenir fuera del territorio mexicano en caso de demandar a alguna compañía, cuya matriz regularmente estaba en su país de origen; los contratos de arrendamiento estaban por encima de la Constitución de 1917; las compañías tenían que satisfacer un mercado internacional, sin importar las consecuencias que a su paso dejaran.

En ese sentido, Narciso Bassols dice que las etapas de la nacionalización petrolera dejaron la experiencia de un Estado fortalecido conforme sus actos tuvieron mayor fuerza entre aquello que consideraba nación y pueblo, pero la aplicación de una Constitución nacional tuvo un lento efecto y una debilidad constante, pues partía de un contexto histórico en donde el "territorio mexicano nunca fue propiedad real de un Estado” (Bassols, 2006, p. 31).

De acuerdo con lo que nos indican las fuentes históricas, las palabras de Narciso Bassols cobran sentido, sobre todo por la problemática social y territorial que se vivió en las regiones petroleras de México, en especial en el norte de Veracruz, durante las décadas de 1920 y 1930. Una de las principales consecuencias fue que las mencionadas regiones fueron expuestas a un mercado de tierras basado en la compra, despojo y arrendamiento de tierras, en donde las compañías petroleras obtuvieron una considerable ventaja. Pero, a pesar de la inestabilidad política, el endeble control territorial y administrativo de los gobiernos revolucionarios, así como el creciente poder corporativo y económico de las compañías petroleras extranjeras, hubo casos en los que los propietarios hicieron uso de instrumentos legislativos y jurídicos para defender sus bienes, así como hacer cumplir a las compañías petroleras y al gobierno mexicano tanto la jurisprudencia de las leyes porfiristas como las cláusulas de los contratos privados de arrendamiento, exploración y explotación petrolera.

La principal razón por la que los propietarios hicieron uso de los mencionados instrumentos es que tenían un derecho histórico a la tierra, el cual sustentaba su 
legitimidad como usufructuarios, pues antes de que se decretaran las leyes de 1857 y 1917 ya habían iniciado actividades económicas con base en la explotación de recursos naturales que se hallaban dentro de sus propiedades.

Por otro lado, es importante mencionar que existe una larga tarea por desarrollar en el ramo jurídico de la industria petrolera, pues hay que tomar en cuenta también las denuncias promovidas por el sector agroganadero dada la afectación de sus tierras, la lucha por la captación de impuestos entre gobiernos estatales y federales e invasión de tierras nacionales. En la medida que estas aristas sean resueltas, hablaremos de un proceso legislativo y jurídico mucho más detallado que ayude a la mayor comprensión del sentido político y social de la industria petrolera.

\section{REFERENCIAS DOCUMENTALES Y BIBLIOGRAFÍA}

\section{Archivos}

AHP: Archivo Histórico de PEMEX. Ciudad de México, México.

Fondo: Expropiación.

AGEV: Archivo General del Estado de Veracruz. Xalapa, Veracruz, México.

Fondos: Comisión Agraria Mixta y Almanza.

\section{Decretos}

Constitución Política de los Estados Unidos Mexicanos (1934). Distrito Federal, México: Talleres Gráficos de la Nación.

Gaceta Oficial (2 de febrero de 1915). Xalapa, Veracruz, México. Gobierno del Estado de Veracruz.

Ley y Reglamento sobre Petróleo (31 de diciembre de 1925). Diario Oficial. Distrito Federal, México.

Reglamento de la Ley del Petróleo (8 de abril de 1926). Diario Oficial. Distrito Federal, México.

\section{Bibliografía}

Alemán, M. (1977).La verdad del petróleo en México. Distrito Federal, México: Editorial Grijalbo. 
Bassols, N. (2006). Las etapas de la nacionalización petrolera. Distrito Federal, México: Editorial Porrúa.

Brown, J. (1998). Petróleo y Revolución en México. Distrito Federal, México: Siglo Veintiuno Editores.

Cosío, D. (1965). Historia moderna de México. Distrito Federal, México: Editorial Hermes.

Fow LER, S. (1979). Movilización campesina en Veracruz (1920-1938). Distrito Federal, México: Siglo Veintiuno Editores.

García, I. (2009). Historia de la visión territorial del Estado mexicano. Guadalajara, Jalisco, México: Universidad de Guadalajara.

García, L. (1989). Realidad y demagogia en la tecnología mexicana. Distrito Federal, México: Premia Editora.

GARner, P. (2007). Leones británicos y águilas mexicanas. Negocios, politica e imperio en la carrera de Weetman Pearson en México, 1889-1919. Distrito Federal, México: Fondo de Cultura Económica.

López, P. (1975). El petróleo de México. Distrito Federal, México: Fondo de Cultura Económica.

Meyer, L. (1990). Petróleo y nación (1900-1987). La politica petrolera en México. Distrito Federal, México: Fondo de Cultura Económica.

Meyer, L. (1972). México y Estados Unidos en el conflicto petrolero (1917-1942). Distrito Federal, México: El Colegio de México.

Meyer, L. (1978). Historia de la Revolución mexicana, 1928-1934: El conflicto social y el Maximato. Distrito Federal, México: El Colegio de México.

Petróleos Mexicanos (1988). El petróleo. Distrito Federal, México: Petróleos Mexicanos. Petróleos Mexicanos (1988). Mensaje a la nación. Decreto expropiatorio, Marzo 18, 1938.

Distrito Federal, México: Petróleos Mexicanos.

Santiago, M. (2006). The ecology of oil: Environment, labor, and de Mexican Revolution, 1900-1938. Nueva York, Estados Unidos: Cambridge University Press.

Serna, A. (2008). Manuel Peláez y la vida rural en la Faja de Oro. Petróleo, revolución y sociedad en el norte de Veracruz, 1910-1928. Distrito Federal, México: Instituto de Investigaciones Dr. José María Luis Mora.

Velasco, J. (1993). Politica y legislación agraria en México. De la desamortización civil a la reforma campesina. Xalapa, Veracruz, México: Universidad Veracruzana.

ZEA, L. (1968). Elpositivismo en México: Nacimiento, apogeo y decadencia. Distrito Federal, México: Fondo de Cultura Económica. 